\title{
The transcriptome of the rumen ciliate Entodinium caudatum reveals some of its metabolic features
}

Lingling Wang ${ }^{1}$, Anas Abu-Doleh²,3,4, Johanna Plank', Umit V. Catalyurek ${ }^{2,3,5}$, Jeffrey L. Firkins ${ }^{1}$ and Zhongtang $\mathrm{Yu}^{1 *}$ (D)

\begin{abstract}
Background: Rumen ciliates play important roles in rumen function by digesting and fermenting feed and shaping the rumen microbiome. However, they remain poorly understood due to the lack of definitive direct evidence without influence by prokaryotes (including symbionts) in co-cultures or the rumen. In this study, we used RNA-Seq to characterize the transcriptome of Entodinium caudatum, the most predominant and representative rumen ciliate species.

Results: Of a large number of transcripts, > 12,000 were annotated to the curated genes in the NR, UniProt, and GO databases. Numerous CAZymes (including lysozyme and chitinase) and peptidases were represented in the transcriptome. This study revealed the ability of E. caudatum to depolymerize starch, hemicellulose, pectin, and the polysaccharides of the bacterial and fungal cell wall, and to degrade proteins. Many signaling pathways, including the ones that have been shown to function in E. caudatum, were represented by many transcripts. The transcriptome also revealed the expression of the genes involved in symbiosis, detoxification of reactive oxygen species, and the electron-transport chain. Overall, the transcriptomic evidence is consistent with some of the previous premises about E. caudatum. However, the identification of specific genes, such as those encoding lysozyme, peptidases, and other enzymes unique to rumen ciliates might be targeted to develop specific and effective inhibitors to improve nitrogen utilization efficiency by controlling the activity and growth of rumen ciliates. The transcriptomic data will also help the assembly and annotation in future genomic sequencing of E. caudatum.

Conclusion: As the first transcriptome of a single species of rumen ciliates ever sequenced, it provides direct evidence for the substrate spectrum, fermentation pathways, ability to respond to various biotic and abiotic stimuli, and other physiological and ecological features of E. caudatum. The presence and expression of the genes involved in the lysis and degradation of microbial cells highlight the dependence of E. caudatum on engulfment of other rumen microbes for its survival and growth. These genes may be explored in future research to develop targeted control of Entodinium species in the rumen. The transcriptome can also facilitate future genomic studies of $E$. caudatum and other related rumen ciliates.
\end{abstract}

Keywords: Entodinium caudatum, Metabolism, RNA-Seq, Rumen protozoa, Transcriptomics

\footnotetext{
*Correspondence: yu.226@osu.edu

'Department of Animal Sciences, The Ohio State University, 2029 Fyffe Court,

Columbus, $\mathrm{OH} 43210$, USA

Full list of author information is available at the end of the article
}

(c) The Author(s). 2019 Open Access This article is distributed under the terms of the Creative Commons Attribution 4.0 International License (http://creativecommons.org/licenses/by/4.0/), which permits unrestricted use, distribution, and reproduction in any medium, provided you give appropriate credit to the original author(s) and the source, provide a link to the Creative Commons license, and indicate if changes were made. The Creative Commons Public Domain Dedication waiver (http://creativecommons.org/publicdomain/zero/1.0/) applies to the data made available in this article, unless otherwise stated. 


\section{Background}

Rumen protozoa are strictly anaerobic and highly specialized ciliates that can survive only in the rumen and similar habitats [1]. These ciliates play important roles in feed utilization and impact the environmental footprint (methane emission and nitrogen excretion) of ruminant livestock production [2,3]. Although numerically much less abundant than rumen bacteria, rumen ciliates account for a large portion of the total microbial biomass due to their large cell size. In the rumen of domesticated cattle and sheep, rumen ciliates collectively account for 20 to $50 \%$ of the total microbial biomass [4]. Throughout millions of years of evolution, rumen ciliates developed symbiotic relationships with their animal hosts and both symbiotic and predator-prey relationships with other members of the rumen microbiota. Researchers began to study rumen ciliates in the 1950s [5, 6] and made repeated attempts to establish axenic cultures (a culture free of bacteria, archaea, and fungi) of individual rumen ciliate species to definitively characterize their metabolism, physiology, and ecology. However, no one has succeeded in establishing an axenic culture of any rumen ciliate species that can be maintained long enough (typically no longer than a week) for research [7-9]. The lack of axenic cultures of rumen ciliates has forced researchers to utilize other methods to infer metabolism and functions of rumen protozoa, such as comparing the rumen fermentation and microbial profiles of faunated and defaunated (ciliate free) cattle or sheep, or using in vitro cultures of washed rumen ciliate cells, which still contained unknown (both taxonomically and quantitatively) prokaryotic species. Because of the unknown confounding factors, such as variations of rumen microbiome in the absence or presence of protozoa and potential prokaryotic contamination, the fundamental biological characteristics of rumen protozoa remain to be definitively determined. For example, their substrate spectrum, fermentation products, metabolic pathways, recruitment of symbionts, and prey selection all remain to be fully elucidated. As another example, rumen ciliates are thought to scavenge $\mathrm{O}_{2}$ that enters the rumen (together with the ingested feed, drinking water, saliva, and perfusion from the rumen wall), thereby protecting strictly anaerobic archaea and bacteria, particularly cellulolytic bacteria [10]. However, it remains to be determined if and how rumen ciliates utilize $\mathrm{O}_{2}$.

Transcriptomics is a powerful tool to reveal the genes expressed in an organism and thus enables characterization of its metabolism and other biological processes and features. Before next-generation sequencing (NGS) technologies became available, the first transcriptomic study of ciliates used sequencing analysis of expressed sequence tags (ESTs) to assess the gene expression of model ciliate Tetrahymena thermophila [11].
Through genome-scale gene discovery and functional analysis, that study greatly advanced the understanding of the biological features of $T$. thermophila. Additionally, it revealed that $11 \%$ of the non-Tetrahymena specific genes were present in humans and other mammals but not found in other model unicellular eukaryotes, reinforcing the status of Tetrahymena as an excellent model for studying many aspects of animal biology. The transcriptome of $T$. thermophila, determined recently using RNA-Seq, provided a fully comprehensive view of its global gene expression [12] and significantly improved its genome annotation [12,13]. Plasmodium falciparum, the protozoan parasite that causes malaria in humans, has been subjected to repeated transcriptomic studies using all the available technologies or approaches, including DNA microarrays [14], cDNA libraries [15], serial analysis of gene expression (SAGE) [16], and RNASeq [17]. These studies enabled a comprehensive understanding of the biological features at each stage of its life cycle, identification of gene targets for drug development, and discoveries of drug resistance mechanisms in $P$. falciparum $[18,19]$.

Three transcriptomic studies have been reported on rumen ciliates. The first study analyzed only a small number of ESTs from 10 species of rumen ciliates [20], and two recent studies analyzed the eukaryotic (both ciliates and fungi) transcripts of an entire ruminal microbiota using a metatranscriptomic approach [21, 22]. These studies provided direct evidence of some metabolic features of rumen ciliates and suggested the high likelihood of horizontal gene transfers (HGT). However, the small number of transcripts determined only revealed a tip of the complex biological iceberg of rumen ciliates. The objectives of the present study were to discover the genes of Entodinium caudatum, a predominant rumen ciliate species, and to gain a better understanding of its metabolism and physiological and ecological characteristics. We used RNA-Seq to analyze a clonal ciliate monoculture of $E$. caudatum MZG-1 as the only ciliate. We found more than 33,000 transcripts that provided new insights into the metabolic and other biological features of E. caudatum.

\section{Results}

\section{Overview of the Entodinium caudatum transcriptome}

From nearly 60 million raw sequencing reads, approximately 21.6 million sequences resulted after filtering with a $Q$ score $\geq 30$ and joining of the paired reads (Additional file 1: Table $\mathrm{S} 1$ ). De novo assembly of the quality-checked sequences using Trinity [23] resulted in 58,899 contigs. After filtering out the contigs with low coverage (less than $5 \times$ ), putative contaminations of prokaryotic transcripts, and other 
uncertain sequences, 33,546 contigs (referred to as transcripts hereafter) remained, with an average length of 759 bases and N50 of 596 bases. About 54\% of the transcripts had low sequence similarity with any of the sequences in the NR or UniProt databases. The relative abundance (\% of total transcripts) of each unique transcript varied considerably. The transcripts at the highest abundance were annotated to coding for proteins involved in cellular structures and processes that are essential to eukaryotic cells (Additional file 2: Table S2). These include (i) histone proteins, such as macronuclear histone; (ii) cell motor and skeleton, such as actin, profilin, tubulin, dynein, and centrin; (iii) signal transduction proteins such as the 14-3-3 protein that binds to many functionally diverse proteins involved in signal transduction; (iv) protein translation; (v) carbohydrate metabolism enzymes such as pyruvate phosphate dikinase (PPDK); and (vi) nucleotide metabolism enzymes such as nucleoside-diphosphate kinase (NDPK). Transcripts annotated to code for proteolysis were also abundant, and these include polyubiquitin- and ubiquitinconjugating enzymes, cysteine proteinase including cathepsins B and F, both of which are lysosomal cysteine peptidases, and cysteine protease inhibitors such as cystatin-B-like protein. Two of the highly expressed cysteine proteinases were annotated to having a signal peptide.
The COG, GO, and KEEG classification of the E. caudatum transcripts

Comparison of the transcript sequences to the COG database using MEGAN5 [24] assigned 4302 different transcripts to all of the 23 COG functional categories (Fig. 1). The largest category was general function (Category R), followed by replication, recombination, and repair (Category L); function unknown (Category S); posttranslational modification, protein turnover, and chaperones (Category O); translation, ribosomal structure, and biogenesis (Category J); signal transduction (Category $\mathrm{T}$ ); cytoskeleton (Category Z); intracellular trafficking, secretion, and vesicular transport (Category $\mathrm{U}$ ); and carbohydrate transport and metabolism (Category G).

Of the 15,724 transcripts that each had an NR hit, 12, 652 were assigned to 8665 non-redundant GO terms. Using the WEGO online tool (wego.genomics.org.cn), these transcripts were annotated to a large number of level-3 subcategories of cellular components, molecular function, and biological processes (Additional file 3: Table S3). Among the highly abundant transcripts annotated to level-3 subcategories of cellular components are cell parts (including intracellular parts, endomembrane systems, cell periphery, and plasma membrane), organelles and organelle parts (e.g., organelle membrane and lumen, membrane-bounded organelles, and nonmembrane-bounded organelles), and protein-containing

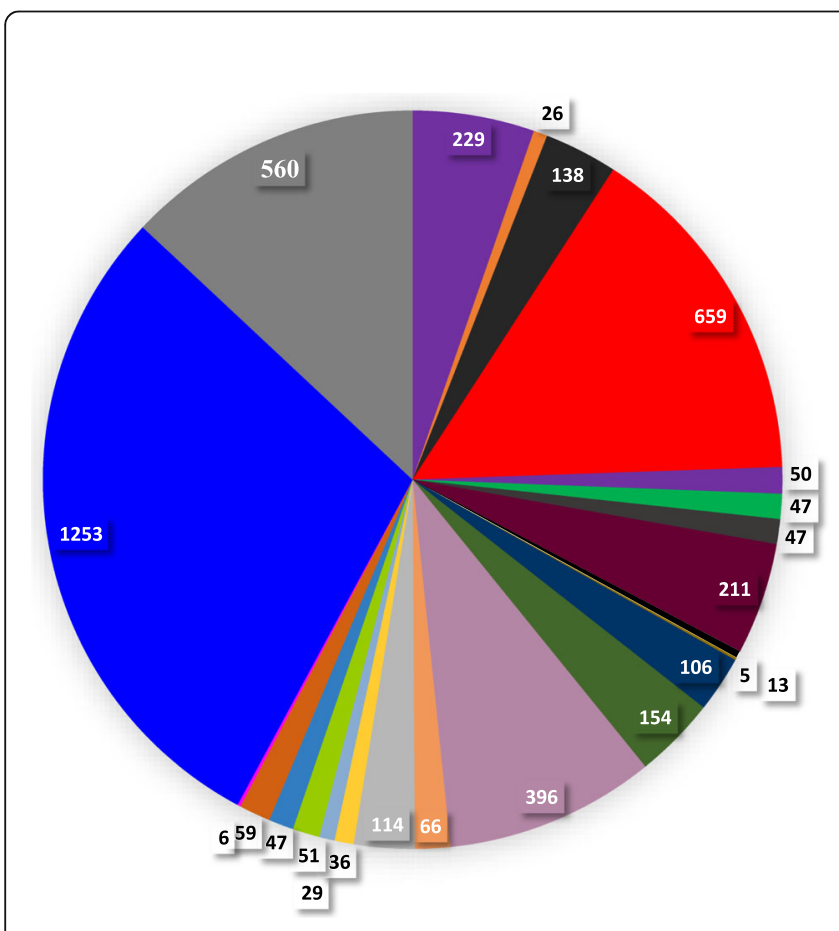

- $[\mathrm{J}]$ Translation, ribosomal structure and biogenesis

- [A] RNA processing and modification

- $[\mathrm{K}]$ Transcription

- [L] Replication, recombination and repair

- $[\mathrm{B}]$ Chromatin structure and dynamics

- [D] Cell cycle control, cell division, chromosome partitioning

- [V] Defense mechanisms

- [T] Signal transduction mechanisms

- $[\mathrm{M}]$ Cell wall/membrane/envelope biogenesis

- $[\mathrm{N}]$ Cell motility

- $[\mathrm{Z}]$ Cytoskeleton

- [U] Intracellular trafficking, secretion, and vesicular transport

- [O] Posttranslational modification, protein turnover, chaperones

- $\quad[C]$ Energy production and conversion

- [G] Carbohydrate transport and metabolism

[E] Amino acid transport and metabolism

- $\quad$ [F] Nucleotide transport and metabolism

- $[\mathrm{H}]$ Coenzyme transport and metabolism

- [I] Lipid transport and metabolism

- [P] Inorganic ion transport and metabolism

- $[\mathrm{Q}]$ Secondary metabolites biosynthesis, transport and catabolism

- [R] General function prediction only

- Function unknown

Fig. 1 COG classification of the E. caudatum transcriptome 
complexes. Other transcripts at high abundance were annotated to genes involved in cell projection parts, cell leading edge parts, apical parts of cells, clathrin-coated pits, cilium and ciliary parts, extracellular organelles and region parts, intraciliary transport particles, proteasome core complexes, proteasome regulatory particles, TOR complexes (both TORC1 and TORC2), and DNA packaging complexes. In the molecular function category, transcripts at high abundance were found encoding catalytic activities (e.g., hydrolases, transferases, oxidoreductases, catalytic activities acting on RNA, and ligases), binding (binding of organic cyclic and heterocyclic compounds, carbohydrate derivatives, small molecules, ions, proteins, lipids, and drugs), molecular function regulators (e.g., regulators of enzymes, guanyl-nucleotide exchange factor activities, and channels), molecular transducers (e.g., signal receptors, cyclin-dependent protein kinases, and cyclic nucleotide-dependent protein kinases), transporters (e.g., transmembrane transporters, lipid transporters, and protein transporters), structural molecules (e.g., protein-containing complex scaffolds, structural constituents of ribosomes, and structural constituents of cytoskeletons), and transcription regulators (DNA-binding transcription factors and transcription coregulators). The biological process has the largest number of transcripts annotated to level-3 subcategories. Among the highly expressed genes were the ones involved in cellular developmental processes, cellular processes (development, components, response, signal transduction, regulation, communication, cell cycle), cellular component organization or biogenesis, localization (establishment, maintenance, regulation), regulation (biological quality, processes, and molecular function), response to stimuli (stress, chemical, biotic, abiotic, external, endogenous, regulation), signaling (signal transduction and regulation, cell-cell signaling), regulation of biological processes, metabolic processes (organic, nitrogenous compounds, biosynthesis, catabolism, and regulation), regulation of biological processes (both positive and negative). One GO term (GO:0061783 peptidoglycan muralytic activity) involved in peptidoglycan degradation was also represented.

By comparing the transcript sequences to the KEGG database, 5598 transcripts were assigned to 1516 functional orthologs (KOs) and further mapped to 343 pathways involved in Cellular Processes $(20.8 \%$ of total transcripts assigned to a KEGG class), Environmental Information Processing (20.4\%), Genetic Information Processing (16.6\%), Human Diseases (25.6\%), Metabolism (12.6\%), and Organismal Systems (22.8\%) (Fig. 2a,

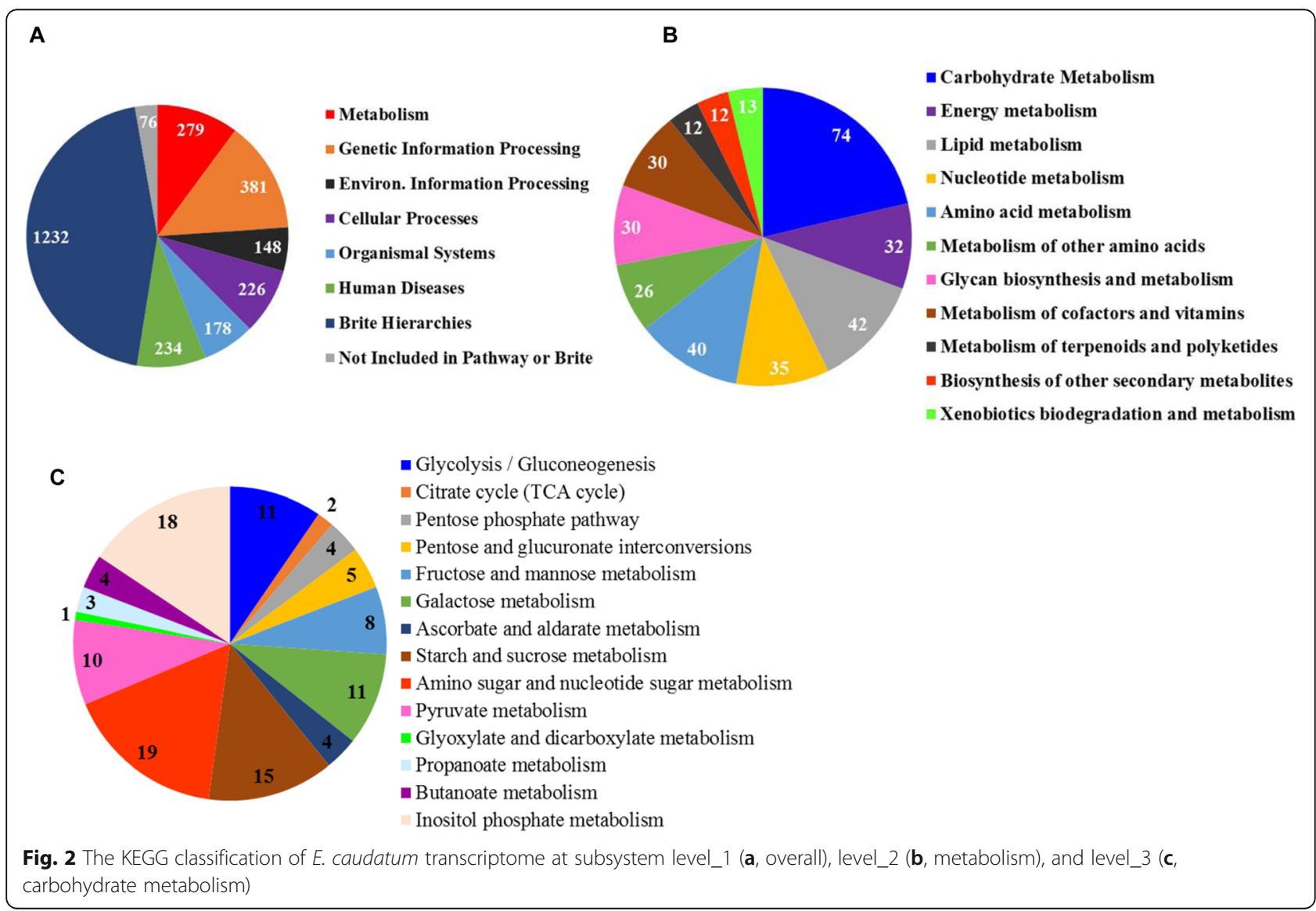


Additional file 4: Table S4). About 250 of the transcripts related to metabolism could not be classified to a pathway or a BRITE (A KEGG BRITE is a collection of manually created hierarchical text (htext) files capturing functional hierarchies of various biological objects, especially those represented as KEGG objects). Within the metabolism category, carbohydrate metabolism was represented by the largest number of transcripts, followed by lipid metabolism, metabolism of cofactors and vitamins, and nucleotide metabolism (Fig. 2b, Additional file 4: Table S4). Of the transcripts involved in carbohydrate metabolism, inositol phosphate metabolism and starch and sucrose metabolism were abundantly represented, followed by galactose metabolism, amino sugar and nucleotide sugar metabolism, pyruvate metabolism, fructose and mannose metabolism, pentose and glucuronate interconversions, and glycolysis (Fig. 2c, Additional file 4: Table S4). The TCA cycle was only represented by two transcripts. Within the Genetic Information Processing category, spliceosome, mRNA surveillance, protein processing in the endoplasmic reticulum, ubiquitinmediated proteolysis, and RNA degradation (besides ribosomes) were among the highly expressed categories. In the Environmental Information Processing category, 32 signaling pathways were represented by varying numbers of transcripts (detailed later in Transcripts involved in signal transductions). Endocytosis, phagosome, lysosome, regulation of autophagy, together with the categories of cell motility, cell cycle, and communication, are the largest subcategories in the Cellular Process category. Only a few transcripts were annotated to de novo biosynthesis of amino acids.

\section{Transcripts involved in carbohydrate metabolism}

Annotations of most of the carbohydrate-active enzyme (CAZyme) transcripts were consistent using both the NR and the UniProt databases (Additional file 5: Table S5). Transcripts were annotated to encoding utilization of starch, hemicellulose, mannan, glycogen, other glucans, pectin, peptidoglycan, chitin, galactoside, raffinose, rhamnoside, and xanthan. Comparison of the transcript sequences to the CAZy database [25] using dbCAN, which employs a hidden Markov model [26], revealed more than 300 transcripts that were annotated to encoding one or more domains characteristic of CAZymes. The predicted CAZymes included one family of Auxiliary Activities, 11 families of Carbohydrate-Binding Module (CBM), 7 families of Carbohydrate Esterase (CE), 28 families of Glycoside Hydrolase (GH), 18 families of Glycosyl Transferase (GT), and 2 families of Polysaccharide Lyase (Table 1). Some transcripts were predicted to bind to peptidoglycan and chitin (annotated to CBM50), starch (CBM20, which has a granular starch-binding function), and xylan (CBM13). Multiple families of acetyl xylan esterase were represented in the transcriptome, together with other esterases. The majority of the CAZymes was associated with degradation of xylan (e.g., GH3 and GH43), starch (GH13, GH31), peptidoglycan (GH18, GH24, and GH25), and chitin (GH18) (Additional file 6: Table S6). Among the GT families, GT38, GT8, and GT4 were each represented by multiple transcripts. They are involved in the degradation of large branched glycan polymers and sugar metabolism. Some transcripts were annotated to encoding swollenin/expansin proteins (Additional file 6: Table S6), which do not have any enzyme activity but can enhance the CAZymes activities [27]. Transcripts encoding the enzymes involved in glycogen synthesis, such as UDP-Glc:glycogen glucosyltransferase, glycogen synthase kinase-3 beta, and 1,4-alpha-glucan-branching enzyme, were well presented (Table 1, Additional file 5: Table S5).

Furthermore, annotation against the NR and the Uniprot databases also identified genes involved in utilization of different sugars and their derivatives, including glucose, mannose, galactose, glucuronic acid, and ribose (Additional file 4: Tables S4 and Additional file 6: Table S6). Except for two genes (the genes encoding phosphoglucose isomerase and fructosebisphosphate aldolase), all the genes of the EmbdenMeyerhof-Parnas (EMP) pathway for glycolysis had corresponding transcripts. Transcripts involved in xylose degradation included those encoding $\mathrm{D}$-xylose 1dehydrogenase and (NADP+)- and NAD(P)H-dependent $\mathrm{D}$-xylose reductases. One transcript was annotated to the pentose phosphate pathway, whereas some transcripts were annotated to pentose and glucuronate interconversions. Transcripts were well represented in the transcriptome that encode the degradative enzymes of $\mathrm{N}$-acetylglucosamine (GlcNAc) and $\mathrm{N}$-acetylmuramic acid (MurNAc), such as GlcNAc kinase, MurNAc-6phosphate etherase (or lyase), and anhydro-GlcNAc kinase. Several transcripts were annotated to trehalose synthesis (e.g., trehalose 6-phosphate synthase) (Additional file 5: Table S5).

Many transcripts were annotated to encoding enzymes involved in the fermentative processes from pyruvate to some of the fermentation products found in the rumen (Fig. 3). The acetate production pathway was represented by pyruvate dehydrogenase bypass (pyruvate metabolic process, GO:0006090) and acetate kinase, with the phosphotransacetylase not being represented. Except for butyryl-CoA dehydrogenase, all the enzymes of the butyrate production pathway were represented (pyruvate carboxylase, acetyl-CoA C-acetyltransferase, 3hydroxybutyrate dehydrogenase, enoyl-CoA hydratase (crotonase), phosphate butyryltransferase, and butyrate kinase). No transcript was found for the acrylate pathway or propanediol pathway of propionate production. 
Table 1 The CAZymes families represented in the Entodinium caudatum transcriptome

\begin{tabular}{|c|c|c|c|}
\hline Family & $\begin{array}{l}\text { NO. } \\
\text { transcripts }\end{array}$ & $S P^{a}$ & Note $^{a}$ \\
\hline AA6 & 1 & 1 & \\
\hline CBM6 & 1 & & \\
\hline CBM13 & 9 & & \\
\hline CBM18 & 1 & & \\
\hline CBM20 & 20 & & \\
\hline CBM32 & 2 & & \\
\hline CBM35 & 1 & & \\
\hline CBM45 & 4 & & \\
\hline $\mathrm{CBM} 50^{\ddagger}$ & 3 & 1 & \\
\hline CBM57 & 2 & 2 & \\
\hline CBM63 & 1 & 1 & \\
\hline CBM67 & 1 & & \\
\hline CE1 & 21 & & \\
\hline CE2 & 1 & & \\
\hline CE3 & 1 & & \\
\hline CE4 & 3 & & $\begin{array}{l}\text { acetyl xylan esterase, deacetylase (chitin, } \\
\text { chitooligosaccharide, peptidoglycan GlcNAc, } \\
\text { peptidoglycan MurNAc) }\end{array}$ \\
\hline CE7 & 10 & & \\
\hline $\mathrm{CE} 10^{+}$ & 23 & 7 & \\
\hline CE14 & 1 & & \\
\hline $\mathrm{GH} 2$ & 6 & & \\
\hline $\mathrm{GH} 3$ & 20 & 7 & \\
\hline GH5 & 2 & 2 & \\
\hline GH9 & 1 & & \\
\hline $\mathrm{GH} 13$ & 33 & 14 & \\
\hline GH16 & 4 & 2 & \\
\hline GH18 & 8 & 6 & chitinase, lysozyme \\
\hline $\mathrm{GH} 24$ & 4 & 1 & lysozyme \\
\hline $\mathrm{GH} 25$ & 20 & 12 & lysozyme \\
\hline $\mathrm{GH} 27$ & 1 & & \\
\hline $\mathrm{GH} 28$ & 1 & & \\
\hline $\mathrm{GH} 30$ & 1 & 1 & \\
\hline $\mathrm{GH} 31$ & 12 & 3 & \\
\hline $\mathrm{GH} 33$ & 1 & 1 & \\
\hline GH38 & 2 & 1 & \\
\hline $\mathrm{GH} 43$ & 2 & 2 & \\
\hline GH53 & 1 & & \\
\hline GH55 & 1 & & \\
\hline GH74 & 1 & 1 & \\
\hline GH76 & 2 & 1 & \\
\hline GH77 & 1 & 1 & \\
\hline $\mathrm{GH} 78$ & 2 & & \\
\hline GH84 & 6 & 6 & $\mathrm{~N}$-acetyl $\beta$-glucosaminidase \\
\hline GH87 & 4 & & \\
\hline GH89 & 1 & & a-N-acetylglucosaminidase \\
\hline GH93 & 6 & & \\
\hline
\end{tabular}

Table 1 The CAZymes families represented in the Entodinium caudatum transcriptome (Continued)

\begin{tabular}{llll}
\hline Family & $\begin{array}{l}\text { NO. } \\
\text { transcripts }\end{array}$ & SPa $^{\text {a }}$ Note $^{\text {a }}$ \\
\hline GH105 & 1 & 1 & \\
GH125 & 3 & \\
GT1 & 1 & \\
GT2 & 38 & \\
GT4 & 10 & UDP-Glc:glycogen glucosyltransferase, ADP-Glc:starch \\
GT5 & 2 & glucosyltransferase, NDP-Glc:starch glucosyltransferase, \\
& & UDP-Glca-1,3-glucan synthase, UDP-Glc:a-1,4-glucan \\
& & \\
GT8 & 14 & \\
GT10 & 1 & \\
GT17 & 5 & \\
GT20 & 3 & \\
GT23 & 2 & \\
GT28 & 1 & \\
GT33 & 1 & \\
GT35 & 1 & \\
GT41 & 1 & \\
GT50 & 1 & lyase (thiopeptidoglycan, pectate, \\
GT69 & 2 & \\
GT75 & 1 & \\
GT83 & 1 & \\
GT92 & 7 & \\
PL8 & 1 & \\
PL9 & 1 & \\
& & \\
\hline
\end{tabular}

a enzymes activities or substrates are indicated for the families that contain lysozyme enzymes and CAZymes that are involved in degradation of chitin and peptidoglycan or synthesis of glycogen

Except for fumarase, all the enzymes involved in succinate production were represented (phosphoenolpyruvate carboxylase, malate dehydrogenase, and fumarate reductase). Some transcripts were annotated to Dlactate dehydrogenase and lactate biosynthetic process (GO:0019249). Some transcripts were found to code for dehydrogenase of aldehyde and alcohol. Formaldehyde dehydrogenase was represented by three transcripts, but no transcript encoded pyruvate formate lyase. Two types of hydrogenases were found: ferredoxin hydrogenase and iron hydrogenase.

\section{Transcripts involved in protein degradation}

Ruminal ciliates engulf large amounts of other microbial cells in the rumen, and E. caudatum is notorious for its high bacterivory [28]. The E. caudatum transcriptome was compared to the MEROPS database (www.ebi.ac.uk/ merops/) to identify putative peptidases (proteases, proteinases, and proteolytic enzymes) and inhibitors. The comparison revealed 615 putative proteinases (Table 2), and some of them were annotated to having a signal 


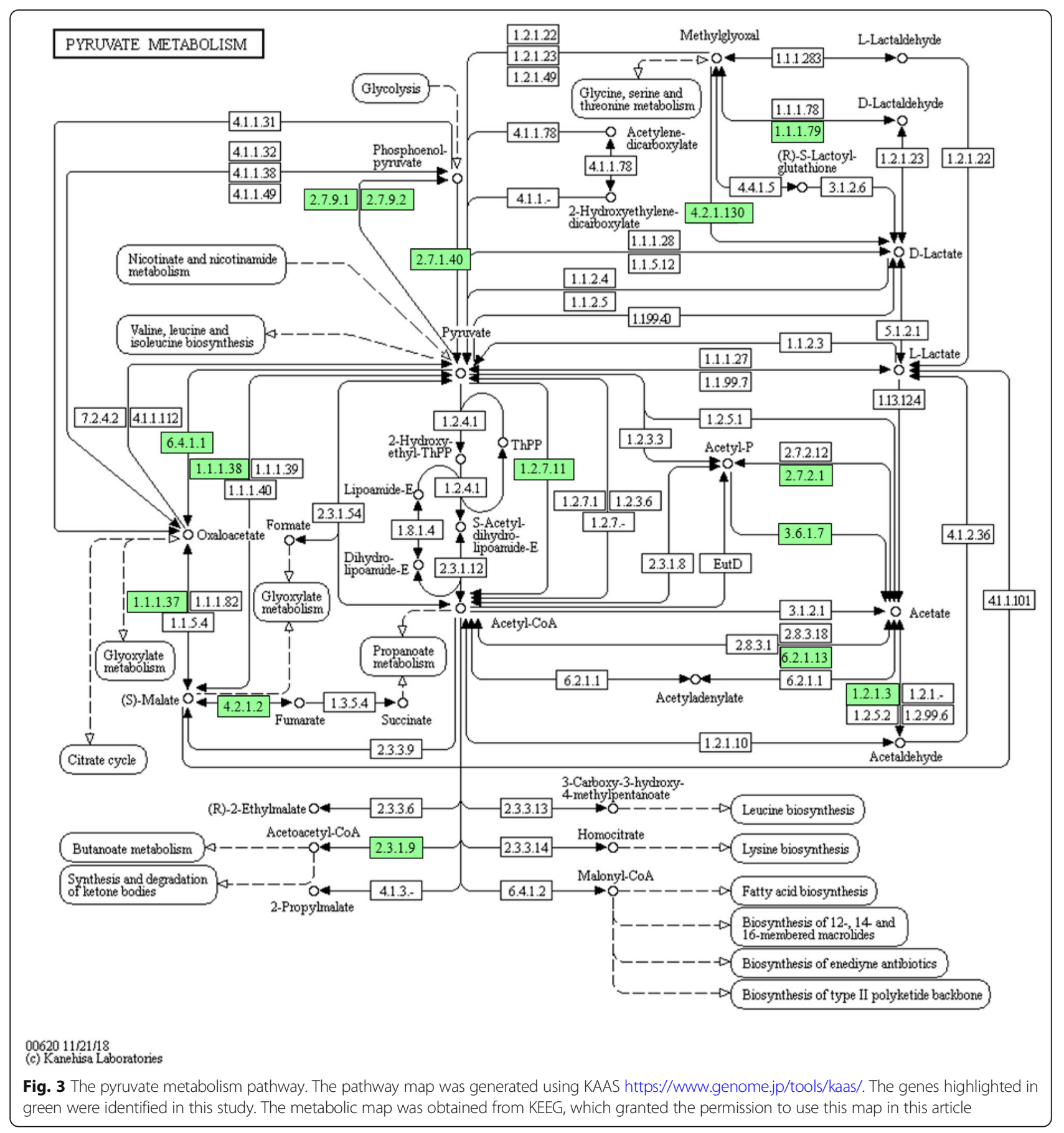

peptide, a transmembrane domain, or both. The putative proteinases were assigned to more than 60 families, and the four major catalytic types of peptidases (cysteine, metallo, aspartic, and serine) each were represented by a large number of transcripts. Among the annotated aspartic peptidases, family A01A had the most transcripts followed by A22A. These two subfamilies contain endopeptidases that are most active at acidic $\mathrm{pH}$ and membrane-inserted endopeptidases, respectively. Family
C19, which is a group of ubiquitin-specific peptidases, was the largest peptidase family among the annotated cysteine peptidases, followed by $\mathrm{C} 01 \mathrm{~A}$, which contains both papain endo- and exo-peptidases, and C02A and C54, which contain calcium-dependent calpain peptidases and endopeptidases, respectively, with specificity for glycyl bonds. Among the annotated metallopeptidase families, M08, which contains zinc metalloendopeptidases and its homologs with acidic $\mathrm{pH}$ optima, followed 
Table 2 Putative proteinase families predicted in the Entodinium caudatum transcriptome

\begin{tabular}{|c|c|c|c|c|c|}
\hline Catalytic Type & Family & No. of Transcripts & No. of transcripts with $\mathrm{SPs}^{\mathrm{a}}$ & No. of transcripts with $\mathrm{TMs}^{\mathrm{b}}$ & No. of transcripts with both SPs and TMs \\
\hline \multirow[t]{7}{*}{ Aspartic (A) } & $\mathrm{A} 01 \mathrm{~A}$ & 27 & 10 & 12 & 7 \\
\hline & A01B & 7 & & 2 & \\
\hline & A02B & 1 & 1 & & \\
\hline & $\mathrm{A} 22 \mathrm{~A}$ & 12 & & & \\
\hline & $A 22 B$ & 4 & & 2 & 1 \\
\hline & A28 & 2 & & 1 & \\
\hline & Total & 52 & & 17 & 8 \\
\hline \multirow[t]{25}{*}{ Cysteine (C) } & $\mathrm{C} 01 \mathrm{~A}$ & 41 & 15 & 6 & 4 \\
\hline & $\mathrm{C} 01 \mathrm{~B}$ & 2 & & & \\
\hline & $\mathrm{CO} 2 \mathrm{~A}$ & 34 & 2 & & \\
\hline & CO4 & 6 & & & \\
\hline & $\mathrm{C} 12$ & 3 & & & \\
\hline & $\mathrm{C} 13$ & 7 & 1 & 3 & 1 \\
\hline & C19 & 222 & 1 & 8 & \\
\hline & $\mathrm{C} 23$ & 2 & & & \\
\hline & $\mathrm{C} 26$ & 9 & 2 & 3 & \\
\hline & $\mathrm{C} 40$ & 8 & 2 & 1 & 1 \\
\hline & C48 & 28 & & & \\
\hline & C50 & 1 & & & \\
\hline & C54 & 32 & & & \\
\hline & C56 & 3 & & & \\
\hline & C59 & 1 & & & \\
\hline & C65 & 3 & & & \\
\hline & C67 & 1 & & & \\
\hline & C69 & 6 & & & \\
\hline & $\mathrm{C} 78$ & 1 & & & \\
\hline & C83 & 1 & & & \\
\hline & C85A & 8 & & & \\
\hline & C87 & 1 & & & \\
\hline & C95 & 4 & 1 & & 2 \\
\hline & C97 & 2 & & & \\
\hline & Total & 422 & 35 & 21 & 8 \\
\hline \multirow[t]{12}{*}{ Metallo (M) } & M01 & 14 & 2 & & \\
\hline & M03A & 3 & & 1 & \\
\hline & M03B & 4 & & & \\
\hline & M08 & 34 & 10 & 5 & 3 \\
\hline & M12B & 1 & & & \\
\hline & M14A & 2 & & & \\
\hline & M14B & 4 & & & \\
\hline & M14D & 2 & & & \\
\hline & M15C & 1 & & & \\
\hline & M15D & 2 & & 1 & \\
\hline & M16A & 9 & & 1 & \\
\hline & M16B & 1 & & & \\
\hline
\end{tabular}


Table 2 Putative proteinase families predicted in the Entodinium caudatum transcriptome (Continued)

\begin{tabular}{|c|c|c|c|c|c|}
\hline Catalytic Type & Family & No. of Transcripts & No. of transcripts with SPs ${ }^{a}$ & No. of transcripts with TMs ${ }^{\mathrm{b}}$ & No. of transcripts with both SPs and TMs \\
\hline & M16C & 2 & & & \\
\hline & M16X & 2 & & & \\
\hline & M18 & 1 & & & \\
\hline & M20C & 1 & & & \\
\hline & M20X & 2 & & & \\
\hline & M24A & 6 & & 2 & \\
\hline & M24B & 1 & & & \\
\hline & M24X & 4 & & 1 & \\
\hline & M28A & 1 & & & \\
\hline & M28X & 1 & & & \\
\hline & M38 & 2 & & & \\
\hline & M41 & 1 & & & \\
\hline & M43A & 1 & & & \\
\hline & M48A & 2 & & 2 & \\
\hline & M54 & 4 & & & \\
\hline & M56 & 1 & & 1 & \\
\hline & M67A & 3 & & 1 & \\
\hline & M76 & 1 & & & \\
\hline & M79 & 4 & & 3 & \\
\hline & Total & 116 & 12 & 17 & 3 \\
\hline \multirow[t]{2}{*}{ Mixed (P) } & P01 & 1 & 1 & & \\
\hline & Total & 1 & 1 & & \\
\hline \multirow[t]{3}{*}{ Serine (S) } & S01A & 4 & & & \\
\hline & S01B & 30 & & & \\
\hline & Total & 34 & & & \\
\hline Total & & 615 & & & \\
\hline
\end{tabular}

${ }^{a} S P$ signal peptide. ${ }^{\mathrm{b}} T M$ transmembrane domains

by M01, which is primarily aminopeptidases. Only two subfamilies of serine peptidases were annotated: S01A and S01B (both are serine endopeptidase). More than 40 transcripts were annotated to coding for peptidase inhibitors (Additional file 7: Table S7). The family I50B (inhibitor of C14) had the most transcripts, followed by I04 (inhibitors of serine and cysteine endopeptidases).

\section{Transcripts involved in signal transductions,} phagocytosis, intracellular trafficking, and vesicular transport

Annotation using both the GO and KEGG databases revealed a large number of transcripts that were mapped to many different signaling pathways, including MAPK, mTOR, PI3K-Akt, AMPK, Wnt, calcium, and Hedgehog signaling pathways (Table 3 and Additional file 3: Table S3, Additional file 4: Table S4, and Additional file 8: Table S8). 14-3-3 proteins, which can bind to a multitude of functionally diverse signaling proteins, including kinases, phosphatases, and transmembrane receptors, were among the highly expressed (Additional file 2: Table S2). The transcriptome contained multiple transcripts annotated to genes of the insulin signaling pathway (Fig. 4).

Many transcripts were annotated to phagocytosis, phagosome, lysosome, the process and structural and functional components that are involved in engulfment and digestion of microbial cells (Additional file 4: Table S4). The highly expressed GO terms included taxis (GO: 0042330), cell motion (GO:0006928), cell mobility (GO: 0048870), MKS complex (GO:0036038), membrane docking (GO:0022406), vesicle (GO:0031982), vesicle targeting (GO:0006903), vesicle-mediated transport (GO:0016192), tethering complex (GO:0099023), ESCRT complex (GO: 0036452), clathrin-coated pit (GO:0005905), and retromer complex (GO:0030904) (Additional file 3: Table S3). Some transcripts were annotated to the phospholipase D signaling pathway (Additional file 8: Table S8), which is involved in regulating membrane trafficking, cytoskeletal reorganization, receptor-mediated endocytosis, exocytosis, and cell migration [29], and SNARE interactions in 
Table 3 Signal transduction pathways predicted for in $E$. caudatum* $^{*}$

\begin{tabular}{|c|c|c|}
\hline PATH ID & Pathway Name & No. of KOs \\
\hline ko02020 & Two-component system & 1 \\
\hline ko04010 & MAPK signaling & 20 \\
\hline ko04012 & ErbB signaling & 10 \\
\hline ko04014 & Ras signaling & 19 \\
\hline ko04015 & Rap1 signaling & 11 \\
\hline ko04020 & Calcium/calmodulin signaling & 10 \\
\hline ko04022 & cGMP-PKG signaling & 13 \\
\hline ko04024 & CAMP signaling & 13 \\
\hline ko04064 & NF-kappa B signaling & 6 \\
\hline ko04066 & HIF-1 signaling & 9 \\
\hline ko04068 & FoxO signaling & 19 \\
\hline ko04070 & Phosphatidylinositol signaling system & 21 \\
\hline ko04071 & Sphingolipid signaling & 19 \\
\hline ko04072 & Phospholipase D signaling & 18 \\
\hline ko04075 & Plant hormone signal transduction & 5 \\
\hline ko04150 & mTOR signaling & 21 \\
\hline ko04151 & PI3K-Akt signaling & 25 \\
\hline ko04152 & AMPK signaling & 19 \\
\hline ko04310 & Wnt signaling & 9 \\
\hline ko04330 & Notch signaling & 3 \\
\hline ko04340 & Hedgehog signaling & 9 \\
\hline ko04350 & TGF-beta signaling & 6 \\
\hline ko04370 & VEGF signaling & 9 \\
\hline ko04371 & Apelin signaling & 19 \\
\hline ko04390 & Hippo signaling & 8 \\
\hline ko04630 & JAK-STAT signaling & 3 \\
\hline ko04668 & TNF signaling & 8 \\
\hline ko04062 ${ }^{a}$ & Chemokine signaling & 13 \\
\hline ko04620 & Toll-like receptor signaling & 7 \\
\hline ko04621 $1^{a}$ & NOD-like receptor signaling & 14 \\
\hline $\mathrm{ko0} 04622^{\mathrm{a}}$ & RIG-I-like receptor signaling & 5 \\
\hline $\mathrm{ko04624^{ \textrm {a } }}$ & Toll and Imd signaling & 3 \\
\hline ko04625 & C-type lectin receptor signaling & 12 \\
\hline ko04910 & Insulin signaling & 18 \\
\hline ko04911 ${ }^{b}$ & Insulin secretion & 4 \\
\hline ko04912 & GnRH signaling & 12 \\
\hline ko04920 b & Adipocytokine signaling & 8 \\
\hline ko04922 ${ }^{b}$ & Glucagon signaling & 10 \\
\hline ko04931 c & Insulin resistance & 14 \\
\hline
\end{tabular}

*This table is a summary of the signal transduction pathways predicted based on both the GO and KEGG database. All the genes assigned to a GO signal transduction categories were further searched in the KEGG database to find their corresponding $\mathrm{KO}$ and pathways involved. All the pathways assigned to a KEGG signal transduction pathway category were listed, plus some other related pathways. ${ }^{a}$, Immune system; ${ }^{b}$, Endocrine system; ${ }^{c}$, Endocrine and metabolic diseases vesicular transport, which is involved in membrane fusion $[30,31]$, were also found (Additional file 4: Table S4).

\section{Transcripts involved in symbiosis and other activities}

Some transcripts were annotated to coding for structures and activities involved in symbionts (Additional file 3: Table S3). These include interspecies interaction between organisms (GO:0044419), host cellular component (GO: 0018995), host cell part (GO:0033643), other organism cell (GO:0044216), adhesion of symbiont to host (GO: 0044406), symbiont-containing vacuole membrane (GO: 0020005), development involved in symbiotic interaction (GO:0044111), growth involved in symbiotic interaction (GO:0044110), dissemination or transmission of organism from other organisms involved in symbiotic interaction (GO:0051821), multi-organism localization (GO:1902579), and movement in environment of other organism involved in symbiotic interaction (GO:0052192).

Some transcripts were annotated to enzymes or proteins involved in activities and features probably particularly unique to rumen ciliates (Additional file 3: Table S3). Many transcripts were annotated to encoding quenching of reactive oxygen species (e.g., GO:0004601, peroxidase activity; GO:0004784, superoxide dismutase activity), regulation of osmolarity (GO:0010118, stomatal movement), cell communication (GO:0007154), cilia and extracellular structure (GO:0030030, cell projection organization; GO:0043062, extracellular structure organization), localization (GO:0051234, establishment of localization; GO:0051235, maintenance of location; GO:0032879, regulation of localization), regulation of circadian rhythm (GO:0042752, GO:0042753), regulation of biological quality (GO:0065008), detection of stimulus (GO:0051606) and response to stimuli (GO: 0006950, response to stress; GO:0006955, immune response; GO:0007610, behavior; GO:0009605, response to external stimulus; GO:0009607, response to biotic stimulus; GO:0009628, response to abiotic stimulus; GO:0009719, response to endogenous stimulus; GO: 0042221, response to chemical stimulus; GO:0051716, cellular response to stimulus; GO:0051707, response to other organisms). Two transcripts were predicted to be involved in conjugation (GO:0000742 karyogamy involved in conjugation with cellular fusion). The dearth of transcripts annotated to conjugation is consistent with binary division being observed as the primary method of reproduction in E. caudatum [32].

\section{Comparison with the genomes of well-characterized ciliates}

This is the first study to characterize the transcriptome of a rumen ciliate. To gain a glimpse of the metabolic features of this symbiotic ciliate, the transcriptome of $E$. caudatum was compared to the macronuclear genomes 


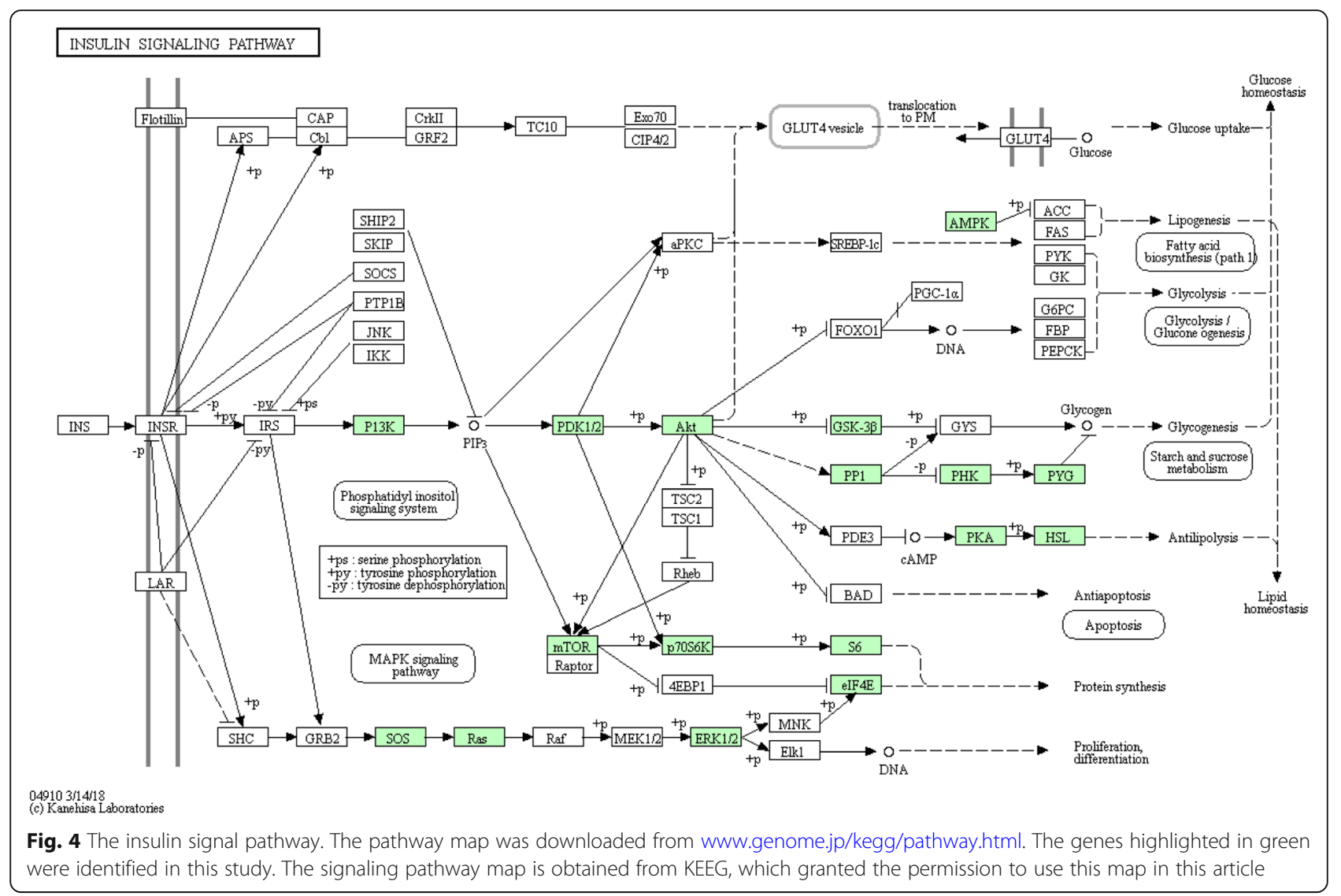

of Paramecium tetraurelia and T. thermophila, two freeliving model aerobic ciliate species, with a focus on the CAZymes and peptidases. Only one-third of the transcripts of the E. caudatum displayed a moderate similarity with the genes of the two free-living model ciliates (Additional file 9: Table S9). Compared to the genomes of these two model ciliates, the E. caudatum transcriptome was enriched with numerous CAZymes (i.e., CBM13, CBM20, CE1, CE10, GH3, GH16, GH18, GT2 GT4, and GT8) and peptidases (C01A, C02A, C19, C26, C54, M01, and S01B).

\section{Discussion}

The rumen is a luxurious environment for anaerobic ciliates because of the rich and consistent availability of substrates and preys (primarily bacteria) and stable temperature and $\mathrm{pH}$ (with some fluctuation but mostly less than half a $\mathrm{pH}$ unit). This transcriptomic study revealed many of the important features of E. caudatum, a common rumen ciliate species. Some of the features related to its metabolism and lifestyle in the rumen are discussed below with a focus on those implicated in the utilization of structural polysaccharides, nitrogen metabolism, and nitrogen utilization efficiency in ruminants. Some of the features help understand the niche and fitness of E. caudatum as a common rumen ciliate. We want to point that that the lack of transcripts annotated to certain enzymes or proteins does not necessarily reflect the lack of the corresponding genes because, to be conservative, we excluded from the bioinformatic analyses the transcripts that had $\leq 5 \times$ sequencing coverage or that were shared a greater than $90 \%$ sequence identity with non-protozoal sequences.

\section{Structural features}

Ciliates are unicellular organisms, and they typically have extracellular structures to protect the cytoplasmic membrane. In T. thermophila and P. tetraurelia, the pellicle serves this purpose. Only one published study [33] has examined the surface structure of one species of rumen ciliate, Isotricha intestinalis. However, that study did not compare or relate the Isotricha intestinalis surface structure to that of the model ciliates. In two early studies, the surface of two rumen ciliates (Epidinium ecaudatum subsp. caudatum and E. caudatum) were referred to as pellicle but offered no description of the structure [34]. Considering the large numbers of transcripts annotated to extracellular structure components, such as cell periphery, extracellular organelles, extracellular matrices, and extracellular region parts, E. caudatum likely has an extracellular structure that is better examined using electron microscopy. Indeed, the extracellular surface structure of E. caudatum was clearly 
revealed by both scanning and transmission electron microscopy in a recent study [9]. A periplasmic space is probably also present between the cell surface structure and the cytoplasmic membrane, as indicated by the transcripts annotated to extracellular and periplasmic space in the E. caudatum transcriptome. In T. thermophila, the trimethylamine $\mathrm{N}$-oxide reductase (TMAO) (TIGR02955) system was found as a periplasmic protein (http://ciliate.org/index.php/feature/details/TTHERM_ 00937640). Another periplasmic protein of T. thermophila is thiol:disulfide oxidoreductase, which is required for disulfide bond formation in proteins that are exported from the cytoplasm [35]. The periplasmic space of E. caudatum is likely a space for multiple activities that await further determination.

\section{Major substrates and metabolism}

Carbohydrates, primarily polysaccharides, are the primary substrates for the rumen microbes, including $E$. caudatum. Mixed cultures of E. caudatum and other rumen microbes are maintained on feedstuffs consisting of starch, cellulose, and hemicellulose $[9,36]$. In the $E$. caudatum transcriptome, the annotated CAZymes included amylases, hemicellulases, cellulases, and pectinases (including pectate lyase). Compared to the genomes of $T$. thermophila and P. tetraurelia, the transcriptome of $E$. caudatum has more genes encoding different CAZymes involved in xylan and starch hydrolysis. Given the much larger numbers of transcripts involved in starch utilization than those involved in the utilization of cellulose and hemicellulose, E. caudatum probably prefers starch, particularly granular starch as indicated by the high expression of CBM20 (binding to starch granules), over other carbohydrates as its major energy source. A recent study did show that E. caudatum engulfed starch granules and converted the digestion products to glycogen [37]. E. caudatum cells isolated and washed from the rumen showed limited abilities to hydrolyze xylan, carboxymethylcellulose (CMC), and cellulose Azure, but not microcrystalline cellulose [38]. The small numbers of GH transcripts annotated to cellulases and hemicellulases reflect the lack of diverse cellulases or hemicellulases. Future research can quantify the expression of the genes encoding these $\mathrm{GHs}$ and their functionality. Three of the transcripts encode swollenin/ expansin-like proteins that are similar to swollenin/ expansin found in the genome of Entamoeba histolytica [39], a protozoan parasite afflicting primates. Expansins are small proteins first discovered in plants, but they were also found in many microbes [27] and the eukaryotic metatranscriptome of the rumen of muskoxen $[20,40,41]$. They do not have hydrolytic activity, but they can bind to and loosen plant cell wall materials to aid fiber hydrolysis [27]. Given the presence of expansin-coding genes in the genome of Entamoeba histolytica [39], which has no known ability to degrade cellulose or hemicellulose, the finding of expansin transcripts in the transcriptome of E. caudatum is intriguing.

Glycogen is the main storage carbohydrate in $E$. caudatum [9, 37], and indeed transcripts encoding glycogen synthesis enzymes (e.g., UDP-Glc:glycogen glucosyltransferase) were identified. The hydrolysis and degradation of glycogen were evidenced by the transcripts encoding the glycogen phosphorylase and glycogen-debranching enzymes. Transcripts were found to be involved in synthesis (e.g., trehalose phosphate synthase) of alpha-trehalose, which can be used as an osmoprotectant by Fabrea salina, a hypersaline ciliate [42]. In Saccharomyces cerevisiae, trehalose is also a storage carbohydrate, a stabilizer and protector of membranes and proteins, a safety valve against damage caused by oxygen radicals, and a regulator of the glycolytic pathway [43]. Given the high osmolarity in the rumen fluid, trehalose likely serves as an osmoprotectant in E. caudatum. However, the possibility of trehalose to be a storage carbohydrate cannot be ruled out.

As a fermentative ciliate, E. caudatum ferments sugars to volatile fatty acids (VFA) and to produce ATP. As indicated by the transcripts involved in the EMP pathway and the pentose pathway, E. caudatum probably uses these two pathways to catabolize hexoses and pentoses, respectively. Acetate, butyrate, and propionate were the major VFA detected in the monocultures of E. caudatum $[44,45]$. However, the monoculture contained prokaryotes of unknown species. No study has reported VFA production by axenic cultures of $E$. caudatum. The finding of transcripts encoding the enzymes involved in the fermentative formation of acetate and butyrate, although one enzyme of each of the pathways was not found, provided transcriptomic evidence for its fermentation profiles from pyruvate. The lack of any transcript annotated to the acrylate pathway or the propanediol pathway suggests that $E$. caudatum does not produce propionate. The high expression of aldehyde dehydrogenase and alcohol dehydrogenase genes also suggests the ability to produce ethanol as a fermentation product. E. caudatum was shown to utilize lactate [46], and this ability is corroborated by the lactate dehydrogenase transcripts. $E$. caudatum probably does not produce formate because no transcript encoded pyruvate formate lyase. No transcript was found to encode acetate:succinate CoA-transferase, the last enzyme mediating acetate formation in hydrogenosomes [47]. This corroborates the previous reports that Entodinium spp. lack hydrogenosomes $[9,48]$. 


\section{Engulfment of other microbes and utilization of their macromolecules}

E. caudatum is the most bacterivorous of the characterized ciliates in the rumen [28]. Many proteins are involved in phagocytosis that involves membrane trafficking and subsequent formation of phagolysosomes [49]. Not surprisingly, a large number of transcripts appeared to be involved in the physiological processes of phagocytosis, phagosome-lysosome trafficking, and regulation of autophagy. No transcript was annotated to mannose 6-phosphate receptor; thus, the lysosomal enzymes are probably transferred to lysosomes via the mannose-6-phosphate receptor-independent pathway(s) [50]. Also, the transcriptome of E. caudatum had a large number of transcripts encoding lysozyme, which were assigned to $\mathrm{GH} 18, \mathrm{GH} 24$, and $\mathrm{GH} 25$, with the latter two $\mathrm{GH}$ families exclusively containing lysozymes. These lysozyme transcripts corroborate the exceptionally high bacterivory of E. caudatum via digesting the peptidoglycan of the bacterial cell wall. Compared to the genomes of $T$. thermophila and P. tetraurelia, the transcriptome of $E$. caudatum has more genes encoding lysozyme, chitinase, and peptidases. This might be attributed to the long-term evolution in the presence of a high density of microbial cells. The transcripts encoding $\mathrm{N}$-acetyl $\beta$ glucosaminidase and $\alpha-\mathrm{N}$-acetylglucosaminidase, both of which are lysosomal enzymes, and GlcNAc kinase, MurNAc-6-phosphate etherase, and anhydro-GlcNAc kinase suggest probable utilization of both the GlcNAc and MurNAc released from peptidoglycan hydrolysis mediated by the lysozyme. This premise is consistent with the degradation of the bacterial cell wall by $E$. caudatum monocultures, although the monoculture contained prokaryotes of unidentified species [51]. The discovery of chitinase transcripts indicated that E. caudatum engulfs and digests fungal cells, and the released fungal GlcNAc may be utilized like the bacterial GlcNAc that is released from the bacterial cell wall. Chitin degradation by protozoa, but not specifically $E$. caudatum, has indeed been reported [52-54]. Engulfment of fungal zoospores by Entodinium sp. has also been observed by scanning electron microscopy [32]. From a nitrogen utilization perspective, lysozyme can be inhibited to decrease the wasteful degradation of microbial proteins to improve nitrogen utilization efficiency in and decrease nitrogen excretion from ruminant livestock.

Many peptidase genes of the four main families were expressed at high levels, suggesting active degradation of the engulfed microbial proteins. Among the peptidases, C19 gene was expressed to the highest level. As a ubiquitin-specific peptidase, it is mainly involved in proteolysis in both the proteasome and the lysosome. It is not certain if the high expression of $\mathrm{C} 19$ gene reflects its role in the proteolysis of E. caudatum proteins or degradation of microbial proteins of the engulfed prey. The subfamily C01A gene also was highly expressed. This subfamily contains papain peptidases, including cathepsins that are lysosomal peptidases. In the transcriptome, cathepsin A, B, D, E, and F were represented. Cathepsin may play an important role in lysosomal degradation of microbial proteins. Three of the four highly expressed cysteine proteinase (C01A, C02A, C19, ad C48) were found to have a predicted signal peptide. These peptidases can be transmembrane proteins within the lysosome or extracellular peptidases. Cysteine proteases with signal peptides were found in $T$. thermophila [55], which secretes proteases [56, 57]. Given the ability to engulf microbial cells, it is intriguing that ciliates may also secrete peptidases. Future research is needed to determine if $E$. caudatum does secrete peptidases. It can be difficult, however, to distinguish the extracellular peptidases secreted from those discharged via the feed digestive vacuoles. Consistent with the rapid degradation and availability of free amino acids derived from microbial protein degradation, only a few transcripts were annotated to de novo synthesis of amino acids, which explains their dependence on bacterial protein as their main protein source [32]. However, small entodinia are often considered the most bacterivorous [3], and the dependence on preformed amino acids may explain the difficulty to grow E. caudatum in axenic cultures [9]. The major families of the peptidases may be targeted to inhibit or control rumen ciliates to improve nitrogen utilization efficiency in ruminants.

Both phagocytosis and feed vacuole movement entail membrane trafficking and recycling. The many transcripts annotated to these processes and lipid metabolism are consistent with that requirement. Numerous transcripts were annotated to being involved in nucleotide metabolism. These transcripts may reflect the complex processes required for the formation of macronucleus or the ability of E. caudatum to degrade and then utilize some of the DNA and RNA of engulfed prey. Because no other rumen microbes conduct phagocytosis, the key enzymes involved in the phagocytosis and the membrane trafficking processes are other potential targets to control rumen ciliates.

\section{Responses to external stimuli, symbiosis, and other features}

Rumen ciliates are known to rapidly respond to external stimuli, including the availability of nutrients [58, 59]. Although transcripts of the common signal transduction pathways are expected as the essential markers of chemotaxis and other responses to external stimuli, it is surprising that the E. caudatum transcriptome was represented by nearly 40 different signaling pathways. Signal transduction mediated by tyrosine kinases and serine/ 
threonine kinase is important to phagocytosis in higher eukaryotes [60], and both kinases were represented by many transcripts in the E. caudatum transcriptome. Few studies have investigated the signal transductions in rumen ciliates. Diaz et al. [61] reported the first study that demonstrated the presence and function of PIK3Akt and the calcium/calmodulin signaling pathways in E. caudatum. Future research may identify signaling pathways that are unique to E. caudatum and other rumen ciliates as potential targets for ciliate control in ruminants.

Rumen ciliates produce hydrogen, thereby forming a positive association with methanogens $[62,63]$. Unlike other ruminal ciliates (e.g., species of Epidinium, Isotricha, and Dasytricha), E. caudatum contains no hydrogenosomes but does contain mitosomes [48, 64]. Malic enzyme, which is found in mitochondria, hydrogenosomes, and mitosomes, was represented in the E. caudatum transcriptome. Multiple transcripts were annotated to mitochondria. Because all the three types of organelles are related phylogenetically [65], the transcripts representing malic enzyme and mitochondria probably reflect the presence of mitosomes, rather than hydrogenosomes, in E. caudatum. Nevertheless, the revelation of iron hydrogenases in the E. caudatum transcriptome underpins hydrogen production by E. caudatum.

Rumen ciliates are assumed to be able to use free oxygen, thereby facilitating the anaerobiosis required for high fiber degradability and fermentation by the strictly anaerobic fibrolytic bacteria and for methanogenesis by archaea. The higher redox potential observed in defaunated than in faunated rumen also suggests the oxygen-scavenging ability of ruminal ciliates [66]. Following washing to remove bacteria, mixed rumen ciliates were shown to consume oxygen [10], and that ability was hypothetically attributed to the ciliates harboring hydrogenosomes, such as holotrichs and some entodiniomorphs [10, 32]. No study has tested if $E$. caudatum can consume oxygen. In the transcriptome, however, multiple transcripts were annotated to NADH dehydrogenase and the electrontransport chain, including cytochrome b5 and its reductase, and the transcripts showed similarity to the genes of Stylonychia lemnae, a free-living aerobic ciliate. Cytochrome $\mathrm{c}$ also had corresponding transcripts. In addition, multiple transcripts were annotated to peroxidases (NADH, glutathione, and thioredoxin peroxidases), suggesting a potential ability, probably very limited, to detoxify hydrogen peroxide. Transcripts annotated to superoxide dismutase related to that of Salpingoeca rosetta, a flagellated eukaryote, was also found. Nitrate reductase was represented by some transcripts and some of the above proteins, including $\mathrm{NADH}$ dehydrogenase and cytochromes, are also involved in nitrate reduction. Future research is needed to experimentally verify if $E$. caudatum can actually utilize free oxygen and/or nitrate as an electron acceptor to conserve energy.

Rumen ciliates were shown to have endosymbionts $[67,68]$, and $E$. caudatum requires some unknown prokaryotic symbionts for its survival [9]. E. caudatum also appeared to harbor specific bacteria, mostly members of phylum Proteobacteria, and these putative symbionts were similar between single $E$. caudatum cells isolated from monocultures maintained for several years in the laboratory and those isolated from fresh rumen fluid [69]. The finding of multiple transcripts annotated to symbiosis supports the symbiotic relationship between E. caudatum and some prokaryotes. As mentioned above, the transcriptome only had a few transcripts involved in de novo biosynthesis of amino acids or nucleosides. Although E. caudatum can obtain amino acids from proteolysis of microbial protein, the symbionts may also provide amino acids and other essential nutrients such as vitamins and other growth factors. Further research is needed to identify the E. caudatum symbionts and their metabolic relationships.

In summary, the transcriptome of $E$. caudatum revealed some of its features with respect to the substrate spectrum, metabolism and fermentation products, potential symbiosis, and oxygen consumption and tolerance. A number of genes that are important to $E$. caudatum but not to other members of the rumen microbiota, such as lysozyme, peptidases, and calcium-dependent protein kinases, the latter of which is expressed only in certain protozoa but not animals [70], may be targeted to develop specific inhibitors to control rumen ciliates to improve nitrogen utilization efficiency. Not all the transcripts can be described and discussed, and some transcripts were annotated to matching non-ciliate genes. Although precautionary steps were taken to remove contamination from other microbes by washing the E. caudatum cells before RNA isolation and removing RNA of other microbes bioinformatically, the transcriptome might still contain RNA sequences from other microbes. Equally plausible, these transcripts could also result from horizontal gene transfers from prokaryotes to rumen ciliates, which have been repeatedly documented $[20,40,41]$. Future genome sequencing will allow confirmation of transcripts of uncertain origin. The transcriptome data will also be valuable to help the assembly and annotation of genome sequences of rumen ciliates. They can also be further analyzed to address specific questions such as the ability to synthesize and the requirement for specific growth factors and circadian rhythm regulation of feeding and activities, both of which have been reported in some rumen protozoa [71-73]. 


\section{Conclusions}

This is the first transcriptomic study of a single species of rumen ciliates. The transcriptome reveals the substrate spectrum, fermentation pathways, ability to respond to various biotic and abiotic stimuli, and other physiological and ecological features of E. caudatum. The high-level expressions of the genes involved in the lysis and degradation of microbial cells highlight the dependence of $E$. caudatum on engulfed rumen microbes for its survival and growth. These genes may be targeted to specifically control the activities and growth of Entodinium species in the rumen to help improve nitrogen utilization by ruminants. The transcriptome can also aid in future genomic studies of E. caudatum and other related rumen ciliates.

\section{Methods}

Strain, RNA extraction, and sequencing

Cells of E. caudatum MZG-1 were collected from a clonal monoculture of $E$. caudatum that was initially established from a single cell isolated from the rumen of gerenuk [36]. It was kindly given to us by Dr. Dehority (deceased). This monoculture does not have detectable fungus. Frozen stock cultures of E. caudatum MZG-1 were cryopreserved at $-80^{\circ} \mathrm{C}$ and have been used in a number of studies $[9,69,74,75]$. The E. caudatum MZG-1 monoculture was fed a mixed feed containing ground wheat grain, ground alfalfa, and ground grass hays and maintained in SP medium [9]. The feeding and transfer procedures were conducted under a continuous stream of $\mathrm{CO}_{2}$ to protect the ciliate cells from exposure to oxygen. Total RNA was isolated from an actively growing E. caudatum MZG-1 monoculture after six hours of incubation at $39^{\circ} \mathrm{C}$ after transferring to fresh SP medium containing the mixed feed. Total RNA was extracted using the Ribozol RNA extraction reagent (Amresco, Inc., Solon, $\mathrm{OH}$ ) and then cleaned up using the RNeasy ${ }^{\circ}$ mini kit according to the manufacturer's instructions (Qiagen, Inc., Valencia, CA). mRNA was enriched using the Oligo Direct mRNA Mini Kit (Qiagen). One library was constructed for $2 \times 100$ paired-end sequencing from the mRNA and then sequenced following the manufacturer's protocol on an Illumina HiSeq 2000 system.

\section{Sequencing data processing, assembly, and gene annotation}

The sequencing data were assembled using Trinity [23]. All the resulting contigs with a length less than $200 \mathrm{bp}$ were discarded prior to further analyses. The coverage of the assembled contigs was estimated using genomecov (http://bedtools.readthedocs.io/en/latest/content/tools/ genomecov.html) in -bga format. The assembled contigs were compared to the non-redundant (NR) protein database of the GenBank (https://www.ncbi.nlm.nih.gov/) and the Uniprot database (http://www.uniprot.org/) using BLASTX with a cutoff e-value less than 1e-5. Because the monoculture was not axenic and contained bacteria and archaea, the resulting annotation results were screened for prokaryotic genes. Singleton contigs and any contigs that had a sequencing coverage of less than $5 \times$ and that shared a greater than $90 \%$ sequence identity with non-protozoal sequences in the public databases were filtered out. Uncertain sequences (with an e-value $\geq 1 \mathrm{E}-10$, no similarity to any eukaryotic genes in the first five hits in sequence comparison) were also discarded because they might be transcripts from other rumen microbes that remained after the decontamination (even though they might be genes transferred from other rumen microbes).

Protein domains were predicted using Pfam (http:// pfam.xfam.org/). Putative proteases were predicted using the online server of the MEROPS protease database (http://merops.sanger.ac.uk/index.htm). Putative CAZymes were predicted using dbCAN, which employs a hidden Markov model [26], against the CAZy database [25]. The contigs were translated to amino acid sequences using TranslatorX [76] using the ciliate nuclear genetic codes [77] and then subjected to prediction of signal peptides and transmembrane domains using the SignalP 4.0 web server (http://www.cbs.dtu.dk/services/SignalP/) and the TMHMM 2.0 web server (http://www.cbs.dtu.dk/services/ TMHMM/), respectively. The transcriptome of $E$. caudatum MZG-1 was also compared to the genome sequences of two model ciliates, $P$. tetraurelia and $T$. thermophila, using BLASTX with a cutoff of $1 \mathrm{E}-10$ to identify shared genes. Gene Ontology (GO) annotations of the transcripts were done using the WEGO web server (http://wego. genomics.org.cn/cgi-bin/wego/index.pl) [78].

The NR annotations of the transcripts were also imported to MEGAN5 $[79,80]$ to predict their COG functional categories and mapped to metabolic pathways using the COG database [81]. Metabolic pathways were reconstructed using KAAS (KEGG Automatic Annotation Server for ortholog assignment and pathway mapping, https://www.genome.jp/tools/kaas/).

\section{Supplementary information}

Supplementary information accompanies this paper at https://doi.org/10. 1186/s12864-019-6382-x.

Additional file 1: Table S1. Summary of the transcriptome of $E$. caudatum. (DOCX 14 kb)

Additional file 2: Table S2. Most highly expressed mRNAs in $E$. caudatum transcriptome.

Additional file 3: Table S3. GO functional classification at subsystem_levels 1 to 3 .

Additional file 4: Table S4. Predicted metabolic pathways of $E$. caudatum based on KEGG. 
Additional file 5: Table S5. The transcripts related to carbohydrate metabolism.

Additional file 6: Table S6. The CAZymes represented in the $E$. caudatum transcriptome.

Additional file 7: Table S7. Putative proteinase inhibitors identified in the E. caudatum transcriptome.

Additional file 8: Table S8. Putative signal transduction pathways predicted from the $E$. caudatum transcriptome.

Additional file 9: Table S9. Comparison of CAZymes and peptidases of E. caudatum transcriptome to the genomes of two model ciliates.

\section{Abbreviations}

AMPK: 5' adenosine monophosphate-activated protein kinase; CAZy: Carbohydrate-active enzymes database; CAZymes: Carbohydrate-active enzymes; CBM: Carbohydrate-binding module; CE: Carbohydrate esterase; CoA: Coenzyme A; COG: Clusters of orthologous group; EMP: EmbdenMeyerhof-Parnas; ESCRT: Endosomal sorting complexes required for transport; EST: Expressed sequence tag; GH: Glycoside hydrolase; GlcNAc: Nacetylglucosamine; GO: Gene ontology; GT: Glycosyltransferase; HGH: Horizontal gene transfer; KEGG: Kyoto Encyclopedia of Genes and Genomes; KO: KEGG orthology; MAPK: Mitogen-activated protein kinase; MEROPS: The peptidase database; mTOR: Mammalian target of rapamycin; MurNAc: N-acetylmuramic acid; NDPK: Nucleoside-diphosphate kinase; NGS: Next-generation sequencing; NR: Non-redundant; Pfam: Protein families; PI3K-Akt: Phosphoinositide-3-kinase and protein kinase B; PL: Polysaccharide lyase; PPDK: Pyruvate phosphate dikinase; SAGE: Serial analysis of gene expression; TCA: Tricarboxylic acid cycle; TMAO: Trimethylamine N-oxide reductase; TOR: Target of rapamycin; TORC: Target of rapamycin complex; UDP-Glc: Uracil-diphosphate glucose; VFA: Volatile fatty acid; WEGO: Web gene ontology annotation plot

\section{Acknowledgments}

The authors would like to acknowledge the support of the Genomics Shared Resources at The Ohio State University.

\section{Authors' contributions}

ZY and JF conceived the study. JP and JF cultured and harvested the protozoan cells. LW did RNA isolation. AAD and UC did the sequence assembly. LW did the annotations and bioinformatic analyses. LW and ZY wrote the manuscript. JF and all the other authors read and approved the final manuscript.

\section{Funding}

This work was partially supported by the National Institute of Food and Agriculture, U.S. Department of Agriculture, under award number 2012 67015-19437. The funding agency played no role in the design of the study; in the collection, analyses, or interpretation of data; or in the writing of the manuscript, or in the decision to publish the result.

\section{Availability of data and materials}

The raw Illumina sequences have been deposited in the Sequence Read Archive of GenBank under the admission number GHEK00000000. The version described in this paper is the first version, GHEK01000000.

\section{Ethics approval and consent to participate}

Not applicable.

\section{Consent for publication}

Not applicable.

\section{Competing interests}

The authors declare that they have no competing interests.

\section{Author details}

'Department of Animal Sciences, The Ohio State University, 2029 Fyffe Court, Columbus, $\mathrm{OH} 43210$, USA. ${ }^{2}$ Department of Biomedical Informatics, The Ohio State University, Columbus, OH, USA. ${ }^{3}$ Department of Electrical and Computer Engineering, The Ohio State University, Columbus, OH, USA.

${ }^{4}$ Current address: Department of Biomedical Systems and Informatics
Engineering, Yarmouk University, Irbid, Jordan. ${ }^{5}$ Current address: School of Computational Science and Engineering, Georgia Institute of Technology, Atlanta, GA, USA.

Received: 12 July 2019 Accepted: 10 December 2019

Published online: 21 December 2019

\section{References}

1. Dehority BA. Rumen Microbiology. Nottingham: Nottingham University Press; 2003.

2. Firkins $J$, , Yu Z. Ruminant nutrition symposium: how to use data on the rumen microbiome to improve our understanding of ruminant nutrition. $J$ Anim Sci. 2015;93(4):1450-70.

3. Newbold CJ, de la Fuente G, Belanche A, Ramos-Morales E, McEwan NR. The role of ciliate Protozoa in the rumen. Front Microbiol. 2015;6:1313.

4. Jouany JP, Ushida I. The role of protozoa in feed digestion: review. Asian Australas J Anim Sci. 1999;12(1):113-28.

5. Sugden B, Oxford AE. Some cultural studies with holotrich ciliate protozoa of the sheep's rumen. J Gen Microbiol. 1952;7(1-2):145-53.

6. Bryant MP, Small N, Bouma C, Robinson I. Studies on the composition of the Ruminal Flora and Fauna of young calves. J Dairy Sci. 1958; 41(12):1747-67.

7. Fondevila M, Dehority BA. Preliminary study on the requirements of Entodinium exiguum and E. caudatum for live or dead bacteria when cultured in vitro. Reprod Nutr Dev. 2001;41(1):41-6.

8. Bonhomme A, Fonty G, Senaud J. Attempt to obtain and maintain rumen entodiniomorph ciliates in axenic cultures. Ann Microbiol (Paris). 1982; 133(2):335-41.

9. Park T, Meulia T, Firkins $J$, Yu Z. Inhibition of the rumen ciliate Entodinium caudatum by antibiotics. Front Microbiol. 2017:8(1189):1189.

10. Ellis JE, Williams AG, Lloyd D. Oxygen consumption by ruminal microorganisms: protozoal and bacterial contributions. Appl Environ Microbiol. 1989:55(10):2583-7.

11. Fillingham JS, Chilcoat ND, Turkewitz AP, Orias E, Reith M, Pearlman RE. Analysis of expressed sequence tags (ESTs) in the ciliated protozoan Tetrahymena thermophila. J Eukaryot Microbiol. 2002;49(2):99-107.

12. Xiong J, Lu X, Zhou Z, Chang Y, Yuan D, Tian M, Zhou Z, Wang L, Fu C,

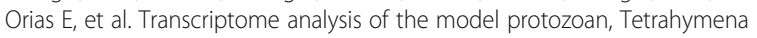
thermophila, using deep RNA sequencing. PLoS One. 2012;7(2):e30630.

13. Coyne RS, Thiagarajan M, Jones KM, Wortman JR, Tallon LJ, Haas BJ, CassidyHanley DM, Wiley EA, Smith JJ, Collins K, et al. Refined annotation and assembly of the Tetrahymena thermophila genome sequence through EST analysis, comparative genomic hybridization, and targeted gap closure. BMC Genomics. 2008;9:562

14. Hayward RE, Derisi JL, Alfadhli S, Kaslow DC, Brown PO, Rathod PK. Shotgun DNA microarrays and stage-specific gene expression in Plasmodium falciparum malaria. Mol Microbiol. 2000;35(1):6-14.

15. Wang Q, Brown S, Roos DS, Nussenzweig V, Bhanot P. Transcriptome of axenic liver stages of Plasmodium yoelii. Mol Biochem Parasitol. 2004;137(1): $161-8$.

16. Patankar S, Munasinghe A, Shoaibi A, Cummings LM, Wirth DF. Serial analysis of gene expression in Plasmodium falciparum reveals the global expression profile of erythrocytic stages and the presence of anti-sense transcripts in the malarial parasite. Mol Biol Cell. 2001;12(10):3114-25.

17. Zhu L, Mok S, Imwong M, Jaidee A, Russell B, Nosten F, Day NP, White NJ, Preiser PR, Bozdech Z. New insights into the Plasmodium vivax transcriptome using RNA-Seq. Sci Rep. 2016;6:20498.

18. Adjalley SH, Scanfeld D, Kozlowski E, Llinas M, Fidock DA. Genome-wide transcriptome profiling reveals functional networks involving the Plasmodium falciparum drug resistance transporters PfCRT and PFMDR1. BMC Genomics. 2015;16:1090.

19. Weissbach T, Golzmann A, Bennink S, Pradel G, Julius Ngwa C. Transcript and protein expression analysis of proteases in the blood stages of Plasmodium falciparum. Exp Parasitol. 2017;180:33-44.

20. Ricard G, McEwan NR, Dutilh BE, Jouany JP, Macheboeuf D, Mitsumori M, Mclntosh FM, Michalowski T, Nagamine T, Nelson N, et al. Horizontal gene transfer from Bacteria to rumen ciliates indicates adaptation to their anaerobic, carbohydrates-rich environment. BMC Genomics. 2006;7:22.

21. Comtet-Marre S, Parisot N, Leperca P, Chaucheyras-Durand F, Mosoni P, Peyretaillade E, Bayat AR, Shingfield KJ, Peyret P, Forano E. Metatranscriptomics 
reveals the active bacterial and eukaryotic Fibrolytic communities in the rumen of dairy cow fed a mixed diet. Front Microbiol. 2017;8(67):67.

22. Sollinger A, Tveit AT, Poulsen M, Noel SJ, Bengtsson M, Bernhardt J, Frydendahl Hellwing AL, Lund P, Riedel K, Schleper C, et al. Holistic Assessment of Rumen Microbiome Dynamics through Quantitative Metatranscriptomics Reveals Multifunctional Redundancy during Key Steps of Anaerobic Feed Degradation. mSystems. 2018;3(4):e00038-18.

23. Haas BJ, Papanicolaou A, Yassour M, Grabherr M, Blood PD, Bowden J, Couger MB, Eccles D, Li B, Lieber M, et al. De novo transcript sequence reconstruction from RNA-seq using the trinity platform for reference generation and analysis. Nat Protocols. 2013;8(8):1494-512.

24. Huson DH, Beier S, Flade I, Górska A, El-Hadidi M, Mitra S, Ruscheweyh HJ, Tappu R. MEGAN Community edition - interactive exploration and analysis of large-scale microbiome sequencing data. PLoS Comput Biol. 2016;12(6): e1004957.

25. Lombard V, Golaconda Ramulu H, Drula E, Coutinho PM, Henrissat B. The carbohydrate-active enzymes database (CAZy) in 2013. Nucleic Acids Res. 2014;42(Database issue):D490-5.

26. Yin $Y$, Mao $X$, Yang J, Chen $X$, Mao F, Xu Y. dbCAN: a web resource for automated carbohydrate-active enzyme annotation. Nucleic Acids Res. 2012; 40(Web Server issue):W445-51.

27. Cosgrove DJ. Microbial Expansins. Annu Rev Microbiol. 2017;71:479-97.

28. Coleman GS, Sandford DC. The engulfment and digestion of mixed rumen bacteria and individual bacterial species by single and mixed species of rumen ciliate protozoa grown in vivo. J Agric Sci. 2009;92(3):729-42.

29. Foster DA, Xu L. Phospholipase D in cell proliferation and cancer. Mol Cancer Res. 2003;1(11):789-800

30. Duman JG, Forte JG. What is the role of SNARE proteins in membrane fusion? Am J Physiol Cell Physiol. 2003;285(2):C237-49.

31. Plattner $\mathrm{H}$. How to design a highly organized cell: an unexpectedly high number of widely diversified SNARE proteins positioned at strategic sites in the ciliate, Paramecium tetraurelia. Protist. 2010;161(4):497-516.

32. Williams AG, Coleman GS. The rumen Protozoa. New York: Springer-Verlag; 1992.

33. Orpin CG, Hall FJ. Surface structures of the rumen holotrich protozoonlsotricha intestinalis with particular reference to the attachment zone. Curr Microbiol. 1983;8(6):321-5.

34. Coleman GS, Hall FJ. The metabolism of Epidinium ecaudatum caudatum and Entodinium caudatum as shown by autoradiography in the electron microscope. J Gen Microbiol. 1974;85(2):265-73.

35. Dorenbos R, Stein T, Kabel J, Bruand C, Bolhuis A, Bron S, Quax WJ, Van Dij JM. Thiol-disulfide oxidoreductases are essential for the production of the lantibiotic sublancin 168. J Biol Chem. 2002;277(19):16682-8.

36. Dehority BA. Physiological characteristics of several rumen protozoa grown in vitro with observations on within and among species variation. Eur J Protistol. 2010;46(4):271-9.

37. Belzecki G, McEwan NR, Kowalik B, Michalowski T, Miltko R. Effect of Entodinium caudatum on starch intake and glycogen formation by Eudiplodinium maggii in the rumen and reticulum. Eur J Protistol. 2017;57:38-49.

38. Coleman GS. The cellulase content of 15 species of entodiniomorphid protozoa mixed bacteria and plant debris isolated from the ovine rumen. $J$ Agric Sci. 1985;104(2):349-60.

39. Loftus B, Anderson I, Davies R, Alsmark UC, Samuelson J, Amedeo P, Roncaglia P, Berriman M, Hirt RP, Mann BJ, et al. The genome of the protist parasite Entamoeba histolytica. Nature. 2005;433(7028):865-8.

40. Newbold CJ, McEwan NR, Calza RE, Chareyron EN, Duval SM, Eschenlauer SC, Mclntosh FM, Nelson N, Travis AJ, Wallace RJ. An NAD(+)-dependent glutamate dehydrogenase cloned from the ruminal ciliate protozoan, Entodinium caudatum. FEMS Microbiol Lett. 2005;247(2):113-21.

41. Qi M, Wang P, O'Toole N, Barboza PS, Ungerfeld E, Leigh MB, Selinger LB, Butler G, Tsang A, McAllister TA, et al. Snapshot of the eukaryotic gene expression in muskoxen rumen--a metatranscriptomic approach. PLoS One. 2011;6(5):e20521.

42. Marangoni R, Paris D, Melck D, Fulgentini L, Colombetti G, Motta A. Understanding UV-driven metabolism in the hypersaline ciliate Fabrea salina. Eur Biophys J. 2012;41(1):107-14.

43. Eleutherio E, Panek A, De Mesquita JF, Trevisol E, Magalhaes R. Revisiting yeast trehalose metabolism. Curr Genet. 2015;61(3):263-74.

44. Park T, Yu Z. Aerobic cultivation of anaerobic rumen protozoa, Entodinium caudatum and Epidinium caudatum. J Microbiol Methods. 2018;152:186-93.

45. Recharla N, Kim D, Ramani S, Song M, Park J, Balasubramanian B, Puligundla $P$, Park S. Dietary multi-enzyme complex improves in vitro nutrient digestibility and hind gut microbial fermentation of pigs. PLoS One. 2019; 14(5):e0217459.

46. Hayirli A, Gulsen N, Umucalilar HD, Alatas MS. Effect of lactic acid on Entodinium caudatum monoculture. Sci Pap Ser D Anim Sci. 2014;LVII: 98-100.

47. van Hellemond JJ, van der Klei A, van Weelden SW, Tielens AG. Biochemical and evolutionary aspects of anaerobically functioning mitochondria. Philos Trans R Soc Lond Ser B Biol Sci. 2003;358(1429):205-13 discussion 213-205.

48. Yarlett N, Coleman GS, Williams AG, Lloyd D. Hydrogenosomes in known species of rumen entodiniomorphid protozoa. FEMS Microbiol Lett. 1984; 21(1):15-9.

49. Guerrier S, Plattner H, Richardson E, Dacks JB, Turkewitz AP. An evolutionary balance: conservation vs innovation in ciliate membrane trafficking. Traffic. 2017;18(1):18-28.

50. von Figura K, Hasilik A. Lysosomal enzymes and their receptors. Annu Rev Biochem. 1986;55:167-93.

51. Belzecki G, Miltko R, Kwiatkowska E, Michalowski T. The ability of rumen ciliates, Eudiplodinium maggii, Diploplastron affine, and Entodinium caudatum, to use the murein saccharides. Folia Microbiol (Praha). 2013;58(6): 463-8.

52. Miltko R, Belzecki G, Herman A, Kowalik B, Skomial J. The effect of rumen ciliates on chitinolytic activity, chitin content and the number of fungal zoospores in the rumen fluid of sheep. Arch Anim Nutr. 2016;70(6):425-40.

53. Miltko R, Belzecki G, Kwiatkowska E, Michalowski T. The ability of the rumen protozoan Eudiplodinium maggii to utilize chitin. Folia Microbiol (Praha). 2010;55(4):349-51.

54. Belzecki G, Miltko R, Michalowski T, Simunek J, Kopecny J. Chitinolytic activity of the sheep rumen ciliate Diploplastron affine. Folia Microbiol (Praha). 2008;53(3):201-3.

55. Karrer KM, Peiffer SL, DiTomas ME. Two distinct gene subfamilies within the family of cysteine protease genes. Proc Natl Acad Sci U S A. 1993;90(7): 3063-7.

56. Banno Y, Yano K, Nozawa Y. Purification and characterization of a secreted protease from Tetrahymena pyriformis. Eur J Biochem. 1983;132(3):563-8.

57. Suzuki KM, Hayashi N, Hosoya N, Takahashi T, Kosaka T, Hosoya H. Secretion of tetrain, a Tetrahymena cysteine protease, as a mature enzyme and its identification as a member of the cathepsin $L$ subfamily. Eur J Biochem. 1998:254(1):6-13.

58. Orpin CG, Letcher AJ. Some factors controlling the attachment of the rumen holotrich protozoa Isotricha intestinalis and I. prostoma to plant particles in vitro. J Gen Microbiol. 1978;106(1):33-40.

59. Diaz HL, Karnati SK, Lyons MA, Dehority BA, Firkins JL. Chemotaxis toward carbohydrates and peptides by mixed ruminal protozoa when fed, fasted, or incubated with polyunsaturated fatty acids. J Dairy Sci. 2014;97(4):2231-43.

60. Kwiatkowska K, Sobota A. Signaling pathways in phagocytosis. Bioessays. 1999;21(5):422-31.

61. Diaz HL, Barr KN, Godden KR, Plank JE, Zapata I, Schappacher AN, Wick MP, Firkins JL. Eukaryotic inhibitors or activators elicit responses to chemosensory compounds by ruminal isotrichid and entodiniomorphid protozoa. J Dairy Sci. 2014;97(4):2254-69.

62. Patra A, Park T, Kim M, Yu Z. Rumen methanogens and mitigation of methane emission by anti-methanogenic compounds and substances. J Anim Sci Biotechnol. 2017;8:13.

63. Belanche A, de la Fuente G, Newbold CJ. Study of methanogen communities associated with different rumen protozoal populations. FEMS Microbiol Ecol. 2014;90(3):663-77.

64. Hackstein JHP, de Graaf RM, van Hellemond JJ, Tielens AGM. Hydrogenosomes of Anaerobic Ciliates. In: Tachezy J, editor. Hydrogenosomes and Mitosomes: Mitochondria of Anaerobic Eukaryotes, vol. 9. Berlin Heidelberg: Springer; 2008. p. 97-112.

65. Tovar J, Fischer A, Clark CG. The mitosome, a novel organelle related to mitochondria in the amitochondrial parasite Entamoeba histolytica. Mol Microbiol. 1999:32(5):1013-21.

66. Jouany JP. Rumen ciliate protozoa; their multiple roles in the digestive tract of ruminants. Endocytobiosis Cell Res. 2006;17:93-102.

67. Lloyd D, Williams AG, Amann R, Hayes AJ, Durrant L, Ralphs JR. Intracellular prokaryotes in rumen ciliate protozoa: detection by confocal laser scanning microscopy after in situ hybridization with fluorescent 165 rRNA probes. Eur J Protistol. 1996;32(4):523-31.

68. Valle ER, Henderson G, Janssen PH, Cox F, Alexander TW, McAllister TA. Considerations in the use of fluorescence in situ hybridization (FISH) and 
confocal laser scanning microscopy to characterize rumen methanogens and define their spatial distributions. Can J Microbiol. 2015;61(6):417-28.

69. Park T, Yu Z. Do Ruminal ciliates select their preys and prokaryotic Symbionts? Front Microbiol. 2018:9(1710):1710.

70. Billker O, Lourido S, Sibley LD. Calcium-dependent signaling and kinases in apicomplexan parasites. Cell Host Microbe. 2009;5(6):612-22.

71. Williams AG, Harfoot CG. Factors affecting the uptake and metabolism of soluble carbohydrates by the rumen ciliate Dasytricha ruminantium isolated from ovine rumen contents by filtration. J Gen Microbiol. 1976;96(1):125-36.

72. Purser DB. A diurnal cycle for Holotrich protozoa of the rumen. Nature. 1961;190:831-2.

73. Michalowski T. Diurnal changes in concentration of rumen ciliates and in occurrence of dividing forms in water buffalo (Bubalus bubalus) fed once daily. Appl Environ Microbiol. 1977;33(4):802-4.

74. Park T, Wijeratne S, Meulia T. Firkins J, Yu Z. Draft Macronuclear Genome Sequence of the Ruminal Ciliate Entodinium caudatum. Microbiol Resour Announc. 2018;7(1):e00826-18.

75. Park T, Yang C, Yu Z. Specific inhibitors of lysozyme and peptidases inhibit the growth of the rumen protozoan Entodinium caudatum without decreasing feed digestion or fermentation in vitro. J Appl Microbiol. 2019; 127(3):670-82.

76. Abascal F, Zardoya R, Telford MJ. TranslatorX: multiple alignment of nucleotide sequences guided by amino acid translations. Nucleic Acids Res. 2010;38(Web Server issue):W7-13.

77. Jukes TH, Osawa S. Evolutionary changes in the genetic code. Comp Biochem Physiol B. 1993:106(3):489-94.

78. Ye J, Fang L, Zheng H, Zhang Y, Chen J, Zhang Z, Wang J, Li S, Li R, Bolund L, et al. WEGO: a web tool for plotting GO annotations. Nucleic Acids Res. 2006;34(Web Server issue):W293-7.

79. Huson DH, Auch AF, Qi J, Schuster SC. MEGAN analysis of metagenomic data. Genome Res. 2007;17(3):377-86.

80. Huson DH, Weber N. Microbial community analysis using MEGAN. Methods Enzymol. 2013;531:465-85.

81. Tatusov RL, Galperin MY, Natale DA, Koonin EV. The COG database: a tool for genome-scale analysis of protein functions and evolution. Nucleic Acids Res. 2000;28(1):33-6.

\section{Publisher's Note}

Springer Nature remains neutral with regard to jurisdictional claims in published maps and institutional affiliations.

Ready to submit your research? Choose BMC and benefit from:

- fast, convenient online submission

- thorough peer review by experienced researchers in your field

- rapid publication on acceptance

- support for research data, including large and complex data types

- gold Open Access which fosters wider collaboration and increased citations

- maximum visibility for your research: over $100 \mathrm{M}$ website views per year

At $\mathrm{BMC}$, research is always in progress.

Learn more biomedcentral.com/submissions 